2015-02

Investigating Children's Spiritual

Experiences through the Health and

Physical Education (HPE) Learning

Area in Australian Schools

Lynch, T

http://hdl.handle.net/10026.1/6305

10.1007/s10943-013-9802-2

Journal of Religion and Health

All content in PEARL is protected by copyright law. Author manuscripts are made available in accordance with publisher policies. Please cite only the published version using the details provided on the item record or document. In the absence of an open licence (e.g. Creative Commons), permissions for further reuse of content should be sought from the publisher or author. 


\section{Investigating Children's Spiritual}

Experiences through the Health and Physical Education (HPE) Learning Area in Australian Schools

\section{Timothy Lynch}

Journal of Religion and Health

ISSN 0022-4197

J Relig Health

DOI 10.1007/s10943-013-9802-2

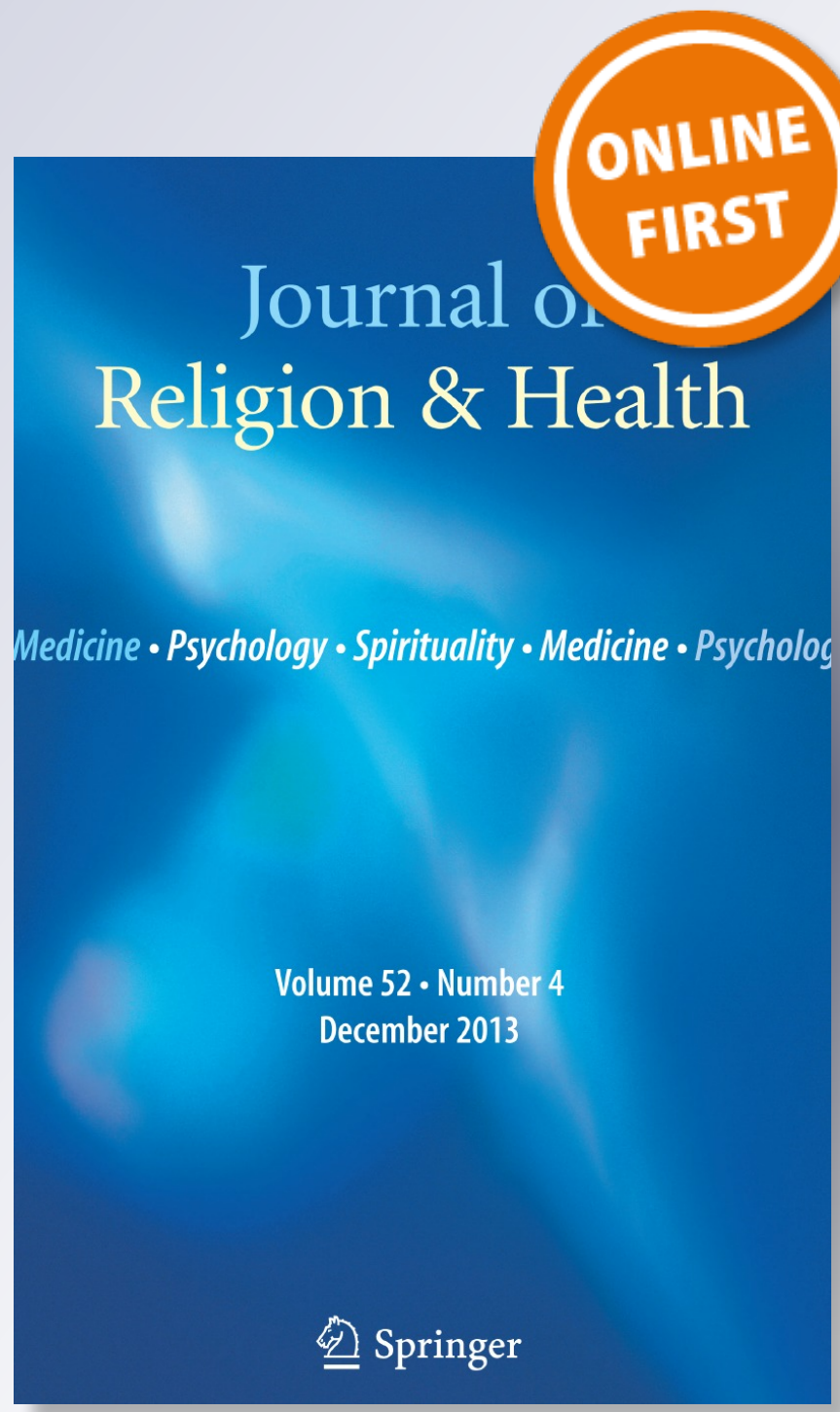

Springer 
Your article is protected by copyright and all rights are held exclusively by Springer Science +Business Media New York. This e-offprint is for personal use only and shall not be selfarchived in electronic repositories. If you wish to self-archive your article, please use the accepted manuscript version for posting on your own website. You may further deposit the accepted manuscript version in any repository, provided it is only made publicly available 12 months after official publication or later and provided acknowledgement is given to the original source of publication and a link is inserted to the published article on Springer's website. The link must be accompanied by the following text: "The final publication is available at link.springer.com". 


\title{
Investigating Children's Spiritual Experiences through the Health and Physical Education (HPE) Learning Area in Australian Schools
}

\author{
Timothy Lynch
}

(C) Springer Science+Business Media New York 2013

\begin{abstract}
The purpose of this study is to explore spirituality within the Health and Physical Education (HPE) learning area, through investigating children's experiences within three Brisbane Catholic Education primary schools (Queensland, Australia). There are seven dimensions of wellness: physical, intellectual, emotional, social, spiritual, environmental, and occupational, which are all strongly connected (Robbins et al. in A wellness way of life, 9th edition, McGraw Hill, USA, 2011). It is logical that HPE, which promotes students to adopt lifelong health and well-being, offers opportunities for spirituality to be experienced and warrants investigation. Data gathered in this qualitative research suggest that regular quality inclusive HPE lessons increased students' potential for spiritual experiences.
\end{abstract}

Keywords Spirituality $\cdot$ Physical education $\cdot$ Holistic health $\cdot$ Children

\section{Introduction}

Throughout history, the Health and Physical Education (HPE) learning area has often been associated primarily with the physical dimension. However, as evidenced by the following excerpt from the recent draft of the Australian curriculum, HPE auspices more than the physical:

In Health and Physical Education students develop the knowledge, understanding and skills to support them to be resilient, to develop a strong sense of self, to build and maintain satisfying relationships, to make health-enhancing decisions in relation to their health and physical activity participation, and to develop health literacy competencies in order to enhance their own and others' health and wellbeing (Australian Curriculum, Assessment and Reporting Authority, 2012, p. 2).

T. Lynch (ه)

Faculty of Education, Monash University, Gippsland Campus, Northways Road, Churchill, VIC 3842, Australia

e-mail: timothy.lynch@monash.edu 
Robbins et al. (2011, p. 9) identify seven dimensions of wellness: physical, intellectual, emotional, social, spiritual, environmental, and occupational. Additionally, "there is a strong interconnection amongst these dimensions". The present curriculum for HPE in the North Eastern state of Australia, the Queensland P-10 HPE syllabus, adopted a sociocultural approach to learning underpinned by social justice principles. Within the curriculum material, "the principles of diversity, equity and supportive environments are highlighted to develop in students an understanding of, and a commitment to, a socially just society" (Queensland School Curriculum Council 1999a, p. 3). As a result, students are assisted to make well-judged decisions in relation to good health and well-being (Queensland School Curriculum Council 1999b). The three strands of the Queensland P-10 HPE syllabus include: enhancing personal development; developing the concepts and skills for physical activities; and promoting the health of individuals and communities.

Spirituality is embedded within all three strands of the HPE curriculum. Within this "holistic" curriculum, the spiritual dimension is defined as "a sense of connection to phenomena and unusual events beyond self and usual sensory and rational existence; a sense of place within the universe" (Queensland School Curriculum Council 1999a, p. 26). The spiritual dimension of wellness is defined as "the personal search for meaning and direction in life" (Robbins et al. 2011, p. 10). Furthermore, there is a strong link between spirituality and one's self-esteem (Robbins et al. 2011). This dimension may be connected to a religion, but it may not. "In its purest sense, spiritual wellness involves cultivating beliefs, principles, and values that provide guidance and strength throughout all of life's experiences" (Robbins et al. 2011, p. 10).

Having accentuated that HPE is more than the physical dimension, it can be argued that the physical dimension does offer unique opportunities and perhaps more so than others, for children in primary schools to experience a "sense of connection", a spiritual dimension. Physical learning and physical activities, as well as being a strand within the HPE curriculum, are valuable components of the students' and schools' culture. Within Catholic schools, a Christian expression of spirituality is considered to be the essential link between faith and culture (Gallagher 1997). Primary schools' culture includes physical learning and physical activities, whether it be learning through movement amongst peers in class with deliberately planned teaching and learning experiences, free play at lunch time or playing inter or intra school sport.

HPE is a foundational Key Learning Area (KLA) in a Catholic primary school as it is with any Australian primary school, recognising the various dimensions of health that develop the students' physical, social, emotional, intellectual, and spiritual growth (Queensland School Curriculum Council 1999b). Catholic education recognises that all dimensions are necessary for the full development of the human person created in the image and likeness of God. Mind, spirit, and body are joined in the profound unity of the human person (Catholic Education Commission, New South Wales 1993). As the context of this research was set in Catholic education, it is assumed that the term spirituality would often refer to a Christian expression of spirituality, although it was understood that this may not be the case for all children. Literature asserts connections between spiritual and physical learning which is to be examined.

\section{Literature Review}

The research problem, "How do HPE offer opportunities for children to experience spirituality?" was investigated. In exploring school responses, it was necessary to understand the relevance of major underpinning themes: 
- Spirituality in modern era Catholic Education;

- Children's spirituality;

- Spirituality and HPE

\section{The Rise of Spirituality in Modern Era Catholic Education}

Spirituality has always existed in Catholic schools; however, it can be argued that recognition of spirituality has become more prevalent in recent times, having "surged into much greater prominence in the social and political life of our world" (Hay and Nye 2006, p. 9). One possible reason for this spiritual focus within Catholic schools is the segregation that often exists between Church and society in contemporary Australia. De Souza (2009, p. 181) shares notions of contemporary spirituality where students' claim to be "not religious but spiritual". Hay and Nye (2006) contend that the "traditional relationship of spirituality with institutional religion has come to seem dubious to many young people, particularly in Western countries" (Hay and Nye 2006, p. 13).

A Christian expression of spirituality within Catholic schools was inspired and encouraged by Vatican II where "evangelisation was to be understood with reference to culture" (Tinsey 2002, p. 11). Vatican II helped change the Catholic Church from a closed society to that of an open society; "A closed society maintains much of its energy and dynamics within the group itself, whereas in an open society a free flow of energy happens within and without the group" (Hater 1994, p. 1). Furthermore, promoting an open society coincided with the extension of community boundaries. Media influences of recent times such as the internet and cable television have extended the boundaries of our world that define the communities that we belong to, impacting upon Catholic schools and parishes (Hughes et al. 1995). This has been further accentuated by globalisation.

Within Catholic schools spirituality has often only been associated with religious education (RE); however, literature suggests that this is a misconception. While it is quite common for people to assume spirituality is synonymous with religion (Robbins et al. 2011; Hyde 2008), considering RE as the only KLA to enable spiritual development is limiting. More so, Berryman (1997, p. 9) states that "Christians, as other traditions, have stunted and distorted children's spirituality by religious education". In addition to this, Buchanan and Hyde (2008, p. 310) maintain that "religious education is one field of study that can effectively address the complementarity between cognitive, affective, and spiritual dimensions of learning". One field of study, implying that spirituality adopting "a holistic approach to learning is possible through all subject areas" (p. 310). Furthermore, Hyde (2008) contends that spirituality is expressed outside of religion in schools, and Malone and Ryan (1994) assert that the community of the Catholic school is often taught informally and within other KLAs.

It can be argued that the HPE learning area offers many opportunities for children's learning within the spiritual. Buchanan and Hyde (2008, p. 312) establish that this dimension "has come to be understood in terms of the connectedness, or relationship an individual has with self, others, the world, and possibly with the Transcendent, named in the Christian tradition as God." It is important to note that the Transcendent may be referred to as the Christian term of God within Catholic education, and while this may be the case for some children, it most likely will not be for all children in contemporary Catholic primary schools. Catholic schools educate approximately one in five school students in Australia (Australian Bureau of Statistics 2010; MCEETYA 1995) and therefore influence a large percentage. 
The growth of spirituality within Catholic schools has evolved during times where the Catholic identification in schools has been forced to undergo major changes (Crotty 1998). This has been a challenge for RE. "Educators need to recognise that existing practices and school structures which worked in the past are no longer viable for the changed context of a world dominated by political, technological and global concerns" (de Souza 2005, p. 40). Post-modern experiential religious education approaches (Imbrosciano 2000) have resulted in less focus on the Church doctrines and more on the spirituality of the people who belong to the Church. As the world continues to change, so must the approaches and programmes in the search for balance and the HPE KLA may hold particular significance and valuable spiritual experiences for children which would open many possibilities for the teaching practice within Catholic education as well as other religious and non-religious schools.

\section{Children's Spirituality}

Spirituality is an essential aspect of all human beings which needs to be given the opportunity to grow (Lavery and Hay 2004). This is axiomatically the same situation for children, where spirituality is an essential part of child development (Hay and Nye 2006). There are numerous definitions of spirituality, and the same can be said about spirituality experienced in a primary school (Mountain 2011). As mentioned earlier, Hyde (2008) suggests that the Catholic education system has done little to describe what is meant by spirituality, yet it is advocated that spirituality promotes inner well-being and wholeness (Lavery and Hay 2004). Harris (2007, p. 264) defines children's spirituality as, "transformational, directive, and peer-relational which involves actively living by being innately connected to a natural source within the moral universe and affectively belonging with relationships that are interconnected within a child's culture and community". The concepts of relationships, self, community, and culture are recurring themes.

When exploring children's experiences of spirituality, it is vital to understand how this may exist and appear. Hyde (2008) identifies four characteristics of children's spirituality;

- The felt sense,

- Integrating awareness,

- Weaving the threads of meaning, and

- Spiritual questing

The first characteristic, "the felt sense", involves physicality and bodily awareness and is the most applicable for the purpose of this study; "Individuals encounter and act upon the world with the whole of their bodies" (Hyde 2008, p. 120). Hyde et al. (2012) profess that young children often are unable to articulate verbally their thoughts; subsequently, they become "far more in tune with their physicality" (p. 3) using "non-verbal avenues, such as laughter, crying, play and the like" (Hyde et al. 2012, p. 3).

The 'felt sense' was professed by Gendlin an American psychotherapist:

Individuals encounter and act upon the world in which they live with the whole of their bodies. He called this focusing, maintaining that it involved attending to the bodily awareness of situations, persons and events. Such bodily awareness is not a mental experience, but a physical one. It doesn't come from thoughts, words or other separate components, but rather as a single, though sometimes puzzling and complex, bodily feeling. Attending to one's own body may then assist with personal difficulties and in being sensitively aware in relationships with others. (Hyde et al. 2012, p. 2) 
"The felt sense" is defined as "the way in which a child draws on the wisdom of her or his own body as a natural and primal way of knowing. It involves an awareness of the immediacy of experience and tactile, sensory activity" (Hyde 2010, p. 510). The significance of this characteristic for children involved in HPE physical activity lessons is axiomatic. According to Hyde et al., "The challenge for those who work with children is to recognise that many of these activities could be experienced by children as spiritual." (p. 3).

“'Integrating awareness' refers to an emerging level of consciousness enveloping, or integrating, a previous level of awareness. This might typically occur, for example, when a person meditates" (Hyde 2010, p. 511). “Weaving the threads of meaning' refers to the child drawing on her or his own sense of wonder as a means by which to make sense of the world and events from the many and diverse frameworks of meaning that are available" (2010, p. 512). The last characteristic " "spiritual questing', refers to the fact that children are seekers. They are actively searching for a sense of life's meaning and purpose, and this is often reflected in what they claim to value most" (2010, p. 514). Parallels can be drawn with secular spiritual wellness behaviours developed by a child which include:

- Develops an awareness of life verses death

- Develops a sense of the importance and expanse of life

- Begins establishing a value system; can distinguish right from wrong

- Begins showing compassion and forgiveness (Robbins et al. 2011, p. 556)

\section{Spirituality and HPE}

The three strands of HPE can all be affiliated with the religious education curriculum (Lynch 2004). Under the HPE umbrella, physical education sits alongside health education, outdoor education, home economics, and religious education (Macdonald 2003; Macdonald and Glover 1997). As earlier discussed, this is of relevance as the KLA of RE is often associated with spirituality. Hence, this connotes that HPE offers opportunities for an expression of spirituality. In particular, the HPE strand Enhancing Personal Development is an essential curriculum component embedded in Religious Education. The Catholic RE curriculum documents state, "Within the Catholic Christian tradition, personal and social development focuses on the lifelong journey towards wholeness as a person created in the image of God and one who contributes to the common good" (Catholic Education Archdiocese of Brisbane 2003, p. 60). Furthermore, "Religious Education Support Resource for the Early Years-RE and Health and Physical Learning Organising Ideas" (Catholic Education Archdiocese of Brisbane 2010) was designed to promote student "engagement with and reflection upon life experiences and messages within Religion texts to build upon their understanding of physical and spiritual well-being" (p. 5).

Using physical activities to experience, a Christian expression of spirituality is not a new concept. Strong support for physical activity has come from many key figures throughout the history of the Catholic tradition, including St. Paul, Clement of Alexandria, St. Dominic, St. Thomas Aquinas, Pope Pius II, St. Ignatius, Pope Pius XI, Pope Pius XII, Pope Paul VI, and the late Pope John Paul II (Feeney 1995). The late Pope John Paul II was an advocate for physical activities and sports stating "the Church approves and encourages sports [physical activities] seeing in it a form of gymnastics of the body and of the spirit" (John Paul II 1979, p. 4). He also questioned, "Are not these athletic values the deepest aspirations and requirements of the Gospel message?" (John Paul II 1980, p. 10). Physical activities in Catholic primary schools through the mediums of the HPE physical activity strand and sport have the advantage that is affiliated with the child's natural play structure (Grace 2000). This 
is most important as "the early physical learnings form the basis for all other learnings" (Kealey 1985, p. 1). This affiliation has been successfully exploited to nourish children's spirituality through Godly Play method (Berryman 2009; Hyde 2010) in an approach to nurturing spirituality within RE and drama (Grainger and Kendall-Seatter 2003).

The immense potential for learning through movement and how the HPE learning area may offer opportunities for children to experience spirituality in a Catholic primary school is evident within literature which includes curriculum policy documents. The next step in this process is to research whether or not this is the actual experience for children within Catholic primary schools.

\section{Research Design}

Within the constructionist paradigm, an interpretivist study was conducted and more specifically the interpretivist study employed symbolic interactionism. This study enabled the students' to share their stories and voices to be heard. Hence, a qualitative, interpretive study approach is most appropriate for connectedness and relationship elements of spirituality, as meanings are socially constructed: "Social realities are constructed by the participants in their social settings" (Glesne 1999, p. 5). The participants share their experiences and perspectives, which are never wrong. A constructionist epistemology frames the research as meaning-making and was developed from engagement and interaction with the participant students sharing their lived experiences and interpreting those experiences. The key assumptions of symbolic interaction are that "people transmit and receive symbolic communication when they socially interact, people create perceptions of each other and social settings, people largely act on their perceptions, and how people think about themselves and others is based on their interactions" (Neuman 2000, p. 60).

The methodology chosen to construct meanings through capturing the context of each school was "evaluative" and "multiple" case study (Merriam 1998). The sites for the three case studies involved: one small-sized Brisbane Catholic Education (BCE) primary school (less than 200 students); one medium-sized BCE primary school (200-400 students); and one large-sized BCE primary school (over 400 students). The three case studies were selected as representative of their different demographics, pertaining to their size as measured by enrolment numbers, their geographic location and their socio-economic status. The study was a story telling case study as it is a "narrative and descriptive account of an educational event, programme or system which deserves to be told to interested audiences, after careful analysis" (Bassey 1999, 58).

The methods engaged so as to enable precision of details within the chosen theoretical framework were focus group interviews, reflective journal, observations, questionnaires and document analysis. There were three focus group interviews for the student participants within each school/case. One focus group with representatives from a class in the early years, one with representatives from a class in the middle years, and one with representatives from a class in the upper years of each case study school. Maximum variation representation (Glaser and Strauss 1967) involved "identifying and seeking out those who represented the widest possible range of the characteristics of interest for the study" (Merriam 1998, p. 63). This was employed, by means of a questionnaire, to select four student representatives with a high interest level in physical activities (two boys and two girls) and four student representatives with a low interest in physical activities (two boys and two girls). The questionnaire results were confirmed by each focus group's respective classroom teacher. 
As Case Study One School had a total enrolment of less than 200 students, there were fewer students in each sample class from which to choose student representatives. A maximum variation representation process was used, by means of a questionnaire, to select two students with a high interest level in physical activities (one boy and one girl), two students with little interest in physical activities (one boy and one girl), and two students with medium interest in physical activities (one boy and one girl) (Table 4). All interviews were conducted by the researcher, audio taped, and transcribed

The specific questions asked and probed during the focused group interview relating to spiritual experiences were:

- What do children enjoy about HPE lessons?

- What are the benefits of HPE?

- How do HPE lessons link with other learning areas at school?

\section{Verification and Ethical Issues}

There were two ethical clearances that were granted before this interpretive research was conducted. They were an ethical clearance from Australian Catholic University and from BCE. Permission was then granted by each of the case study school principals; each of the early, middle, and upper classroom teachers within each case study school; and consent from the parents of the interested student participants.

A conscious effort was made by the researcher to be fair in the generation of data, in the interpretation of data, in the formulation of theories, and in the presentation of data. As the role of the researcher was that of both author and instrument (Patton 1990), bias was consciously avoided and if recognised, minimised. Fairness was achieved through constant peer debriefing where experienced researchers (supervisors) critically reflected on the process of the data generation and analysis during the research. This took place in the form of discussions and proof reading of detailed research reports. Member checks involved soliciting informants' views as to credibility of findings, and these were utilised to confirm the plausibility and credibility of interpretations. Themes and conclusions were checked within the other data generating methods, for example, a finding during an observation was further explored during an interview. This addresses the issue of public disclosure of processes and gives the themes congruence and verisimilitude (Anfara et al. 2002). Credibility of the study was achieved by employing triangulation, the process for using multiple perceptions to clarify meaning (Stake 1994). The multiple perceptions were obtained from observing and interviewing some of the participants.

\section{Analysis of Data}

An interpretivist data analysis strategy employed for the purpose of this research study was narrative/descriptive analysis. Each individual case was analysed using Wellington's (2000) simplified version of the "Constant Comparative Method for Analysing Qualitative Data" (Fig. 1) and was described. Cross-case analysis was presented at the end of the analysis of each case. Repeating the same analysis process, Wellington's stages (Fig. 1) were used to analyse the data across the case studies. All data findings, of individual case study schools and cross-case analysis, were reported using a narrative/descriptive report (Table 1).

Units of meaning were formed, coded, and categorised with other similar units. Table 2 illustrates a copy of a coded semi-structured interview transcript. 
Fig. 1 General stages in making sense of qualitative data (Wellington 2000, p. 141)

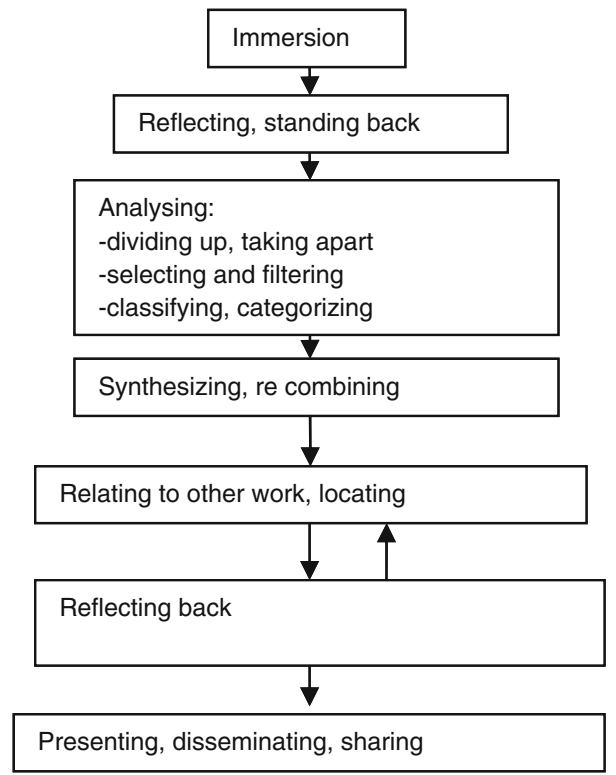

Table 1 Process of data analysis

\begin{tabular}{ll}
\hline Stage 1 & Analysis of data for each case study/school using Wellington's table of analysis \\
Stage 2 & Narrative/descriptive report given as an analysis for each case study \\
Stage 3 & Cross-case analysis again using Wellington's table of analysis. \\
This time analysing whole stories or story sections
\end{tabular}

Table 2 Coding of interview transcript

\begin{tabular}{lll}
\hline & Interview transcript & Coding \\
\hline I & How do HPE lessons link with other learning areas at school? & \\
& RE? & \\
P $\quad \begin{array}{l}\text { It tells us that you have to be kind, not be mean to other people } \\
\text { who are not as good at sport as you. Also to be a good sport, } \\
\text { don't say 'Oh I didn't win' and get all grumpy and walk away } \\
\text { or be mean to others }\end{array}$ & $\begin{array}{l}\text { Gospel values } \\
\text { Tolerance and understanding } \\
\text { Cooperation } \\
\end{array}$ & Acceptance \\
\hline
\end{tabular}

The process of analysis formed an audit trail and is diagrammatically represented in Fig. 2 for students' and teachers' perceptions.

\section{Presentation of Findings}

Summary of Case Study One School (Less than 200 Students)

Case Study One School did not have an HPE specialist teacher, and the teachers were responsible for all three strands of the HPE curriculum. The teachers were all experienced 
Process of Analysis

How do HPE lessons link with other learning areas at school?

STAGE $1 \quad$ Data Generation, display and reflection.

\begin{tabular}{|l|l|}
\hline Participants & Data Generating Strategies \\
\hline Students & Questionnaire \\
& $\begin{array}{l}\text { Focus Group Interview } \\
\text { Observations of lessons } \\
\text { Reflective Journal }\end{array}$ \\
\hline
\end{tabular}

STAGE 2 Data coding and distillation. Themes from data gathered.

\begin{tabular}{|lll|}
\hline - Personal Development and self esteem & - hidden curriculum & - What happens in PE lessons \\
- cooperation and games & - enjoyment with others & - Gospel values \\
- Issues of inclusiveness & - consideration & - tolerance and understanding \\
- acceptance & - lunch time activities & - what they learn at school \\
- favourite aspects of HPE & - benefits of HPE lessons & - importance of HPE \\
\hline
\end{tabular}

STAGE 3 Generation of key themes. Data themes from stage 2 categorised.

\begin{tabular}{|lll|}
\hline - Christian expression of spirituality & - curriculum connections & - quality of implementation \\
- Personal Development strand & - incidental learning & - spiritual dimension \\
- Physical activity strand & - Health strand & - regularity of HPE lessons \\
\hline
\end{tabular}

STAGE $4 \quad$ Story report and conclusions

\begin{abstract}
Early years' student participants in all three case study schools did not verbally connect HPE experiences with other learning areas or elaborate on spiritual concepts during focused group interviews. The majority of upper year student participants and many middle year student participants from all three Case Study schools connected HPE and the RE Christian expression of spiritual concepts. This was mainly through the promotion of Christian Gospel values in the Physical Activity strand. There was an increase in verbal articulation of links in schools that had a HPE designated teacher, where lessons were conducted regularly. Also, spiritual experiences were more freely discussed in greater depth within these schools. In case study three school HPE lessons were conducted weekly but there was evidence of a lack of quality in implementation. Consequently, children identified areas during reflection where they made the wrong choice or could make improvements in social skills or how they connected with others. In case study two school where HPE quality teaching and learning was experienced regularly, spiritual concepts were increased.
\end{abstract}

Fig. 2 Description of data analysis for what children articulate that can be identified as spiritual experiences in Health and Physical Education

teachers, with at least 10 years teaching experience. None of the teachers had specialist training in HPE, and only one had received professional development in the Queensland HPE syllabus. There was no Whole-School Curriculum Programme (WSCP) for HPE (Table 3), and concepts and skills were few and often repeated. Teachers shared that the students had medium interest in physical activities, which was reinforced through observations and focused group interviews (Table 4).

During observations of the HPE lessons in the early years, all children appeared to be enjoying themselves as they were often laughing and smiling. Even the student participants who shared in the interview and questionnaire that they were not interested in HPE appeared to be having an enjoyable time. Some students were willing to demonstrate their rope-skipping skills to the researcher and share that they often practice at home. The activities involved locomotor and non-locomotor movements that the children completed individually were familiar with and competent. As a result, many did not find very challenging. The classroom teacher admitted that she was not very confident at taking HPE lessons and that they did not have them as regularly as they should. The early years' children did not elaborate on the research questions or probing into experiencing spirituality through HPE lessons. While they were engaged with the physical, there was no verbal expression of the connectedness, or relationship with self, others, the world, or the Transcendent. 



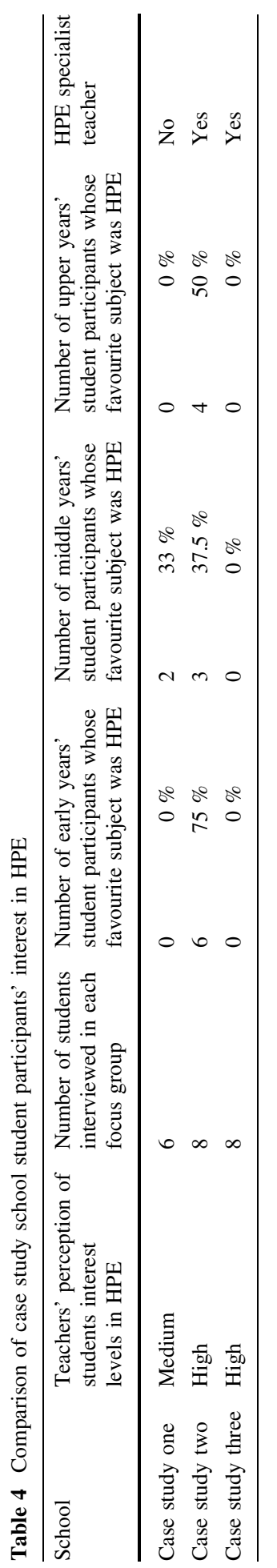


Observations of the middle years' class was once again rope skipping; only this time four stations were used, and the children moved around in groups. While some children were enjoying themselves, it was more obvious that some clearly were bored with this activity. The middle years' children only revealed a small amount during the researchers probing into experiencing spirituality. They shared that they could identify and be more familiar with their confidence through HPE lessons, identify what is good to them personally and what is bad. They also shared that they could make links with how we should treat others through HPE lessons.

The student participants in the upper years of the school practiced ball-passing skills and then played a modified game of netball which enabled maximum participation and was inclusive. While the students thoroughly enjoyed the game, quite a few children were lacking the necessary skills to become fully engaged and appeared to be novices. This was a little surprising considering their age and the level of the skills involved. During the interviews the upper years' students agreed that during physical activities they "used gospel values" but they did not go into details.

\section{Summary of Case Study Two School (200-400 Students)}

Case Study Two School appeared to have a well-designed and implemented Physical Education curriculum programme which both teachers and students believed to be important, beneficial, and enjoyable. The school had an HPE specialist teacher who was responsible for the physical activity strand, and the classroom teachers were responsible for the Health and Personal Development Strands (Table 3). Furthermore, there was a WSCP for the physical activities strand. All teachers felt that the HPE specialist offered a wide range of physical activities and sports within the school which were perceived as a school's strength. For this reason, teachers shared that the students' had high interest in physical activities, which was reinforced through observations and focus group interviews (Table 4). The researcher observed three 40-min lessons being taught. The early years' lesson focus was the Perceptual Motor Programme. Six stations were set up on the basketball court under the covered area. Parent helpers and the PE teacher were at a station each, and sun-safety rules were followed, and modelled by the PE teacher. Activities were explained using cues, and a child demonstrated. Parents were provided with a Jack Capon (Level 2) Perceptual Motor Programme card for their station. The stations comprised fundamental locomotor, non-locomotor, and manipulative skills, involving: a balance activity; jumping, a landing, and rolling activity; an underarm throw activity; dribbling a basketball activity; tracking and striking tennis tether balls with a mini-racquet; and an overarm throw and catching activity. The activities were modified in distance and sides of the body, preferred and non-preferred limbs were alternated to extend capable students. All students ended the lesson with a fun game of Scarecrow tiggy on the grassed area. The children were often involved in the skill or were watching and offering feedback. Hence, there were connections amongst peers and with various parent helpers or the teacher all whom had developed relationships over the weeks. During the semi-structured student participant early years' interviews, the researcher probed for the children to make comments in relation to any spiritual experiences, but there were no links made through verbal expressions.

The middle years' Year-Four class observation lesson took place at the local Junior Rugby field, and again sun-safety rules were followed. The class revised the underarm throw through discussion and questioning when it is used, cues, demonstration, and then practice. The PE teacher positioned the students, so that they were not looking directly into 
the sun, and during the throw practice, he assisted the students with difficulties. The students played "Wicket stump hit" in five groups of five students, where each student had a turn of trying to hit a set of stumps using an underarm and overarm throw, using their preferred and non-preferred arm. The class revised the correct procedure for striking the ball from the tee-ball stand discussing when it is used and cues. The students revised the game of "zigzag tee-ball", a modified game of tee-ball, which was then demonstrated by a group. There were five games of "zigzag tee-ball" occurring simultaneously with five students playing in each group.

When the middle years' focus group was discussing the importance of the HPE learning area, one particular child was focused on the need for training and preparation for events and while initially this appeared to have a physiological reference, as he continued to explain it was as though he was referring to more than just the physical dimension, but a deeper belief, "Um, you feel like you're going do it and like you're not going to stop and it's going to help you run and you're not going to hurt yourself". This very much may have been relating to a connectedness, or relationship an individual has with self, others, the world, or the Transcendent.

The upper years' Year-Six class observation lesson also took place at the Junior rugby field. Again sun-safety and first-aid precautions were mandated. Students revised and demonstrated the skills that had been covered in previous lessons, as they informed the HPE teacher of the cues for marking (catching) a football, overhead and chest; kicking a drop-punt; rugby passing a football; handballing a football and chest passing a netball. The students, in groups of three, practised these skills in a triangle formation using a soccer ball, which replaced the oblongshaped football they had previously used. The teacher assisted the students with difficulties and offered general feedback. Next, the students played a modified game which combined the strategies of Australian Rules football and netball. The field was dissected into thirds, representing forward, back, and centre position zones. The students rotated position zones every $7 \mathrm{~min}$, and only the forward zone players were permitted to score. The game replaced body contact by the use of two strips. Each player wore the strips which if removed when in possession of the ball constituted a tackle. Using a round soccer ball, the students played the modified football/netball invasion game which is similar to Gaelic football.

During the interviews, the upper years' student participants revealed many links between HPE and a spiritual dimension. They discussed this in relation to working with others as part of a team which they all enjoyed and particularly the support of others. One student shared that he preferred team sports to individual: "It's better than individual, because like, if you like, if you make a mistake or something, there are people to help you out and stuff". Another female student agreed, "Um, like what he said, there are people to help you out. But also if you do something wrong it is not just yourself who you do something wrong for, sort of. It is the team as well. So if someone blamed it all on you, the whole team can back you up." All student participants agreed that they do look out, back up, and support their team mates. Another girl mentioned that within cooperative team work, she enjoyed experiencing "good team spirit". She shared that she enjoyed working together and that it was fun to know that you could enjoy working with other people in the group. They believed that the HPE KLA physical activity strand helped "you feel better, about yourself and you have more self-esteem".

\section{Summary of Case Study Three School (Over 400 Students)}

Case Study Three School had an HPE specialist teacher who was responsible mainly for the physical activity strand. The four teaching participants had varying degrees of teaching 
experience. The teacher participants who had begun teaching in the BCE system since 2001 were not familiar with the information in the HPE syllabus. They had not received inservice training within this learning area and indicated that they lacked confidence implementing it. This included the specialist HPE teacher. Furthermore, the beginning years' teacher had no development training within HPE, and there was no WSCP for HPE. All teacher participants reported that the HPE learning area was very valuable, and students appeared to enjoy HPE physical activities. However, the students did not appear to be as interested in the KLA as the teachers perceived them to be (Table 4).

The HPE specialist teacher taught all physical activity lessons that were observed by the researcher. All lessons covered the same concepts and skills of soccer for Years One, Four, and Five. The early years' Year-One class sat down on the steps to the basketball courts where the HPE specialist gave a demonstration of trapping and passing a soccer ball. The students then participated in a trapping and passing drill where they were required to pass the ball to another child positioned at a cone approximately six metres away and then jog down and join the end of the line. This drill and the concept of single lines proved to be too difficult for the majority of the Year-One students. After $5 \mathrm{~min}$, the students sat back down where the HPE teacher informed them that they were going to use the skills of trapping, passing, and dribbling in a game of soccer. Two goals were set up on the court, and the teacher selected four teams. Two teams played while two teams watched on. The students appeared to be familiar with the game although there were very few instructions. The majority of students appeared to be acting upon the world in which they live with the whole of their bodies, focusing. There were no boundary lines, and the teacher refereed alternating teams after the winning team scored. During the semi-structured interview, the early years' children did not share any spiritual connections through verbal expressions, during HPE lessons.

The middle years' Year-Four class began the lesson with a warm up game of "Rats and Rabbits", with the students appearing to be familiar with this game. In this game, slow students who did not complete the exercise in what the PE teacher deemed an acceptable timeframe were required to run laps of the basketball court. After that the students sat on the steps to the basketball court where the HPE teacher demonstrated trapping and passing. They then participated in the same passing and trapping drill as the Year-One class, only the children were then extended by having to pass using their non-preferred foot. The lesson ended with the game of soccer using the same space on the courts that the Year-One class had played. During the focus group interviews, the middle years' student participants shared that the Gospel values that they learnt in religious education related to HPE physical activity lessons. They all agreed that HPE physical activities related to what they learn in Religion about treating others like Jesus did, sharing and cooperating. One girl elaborated on why she said yes: "Because He did help a lot of people. In HPE if people ask you, then you can help them. If they need your help you can be there." Another boy added, "Jesus taught people what is right and wrong. If you do something wrong in HPE you sit out and if you do something right you stay in." Consideration is promoted, "my friend is not that good at soccer, [so] I give her a couple of chances. I show her how to kick". Other children shared "You explain it and like help them." Another example, "my younger cousin is not that good at shooting hoops, when she shoots it goes over the fence so I tell her to come closer and it helps her. As she improves she can move back again". Tolerance was another virtue identified as experienced and promoted through physical activities, "There were two pre-schoolers and I taught them how to play soccer". As well, an appreciation of human potential and acceptance is promoted through realising that at times in HPE some are better than others in certain activities. The students identified that peers have different strengths 
and weaknesses when it comes to physical skills, yet they shared their experiences where they were ridiculed or they ridiculed others. One boy shared, "One time I was playing soccer at After School Care and I had to kick a goal and I missed the ball and then I kicked it again and it didn't get a goal and everybody was laughing at me." When probed he shared that this made him feel most upset and that he did not say anything at the time. Also, that although he understands how people feel when treated this way, there have been times where he has teased others in a similar predicament.

The upper years' Year-Five class began the lesson with a game of "Rats and Rabbits". One girl had a hip problem, so she sat in the shade. Again, students deemed too slow in returning during the game of "Rats and Rabbits" were required to run laps around the basketball court. The students sat down while the HPE teacher demonstrated the passing and trapping drill. The students participated in the same drills as the previous classes. The Year-Five class then played the same soccer game as the previous observed classes. The Year-Five class was quite proficient at the skills of soccer. The upper years' student participants when probed by the researcher had a deep discussion about connectedness, or relationship an individual has with self, others, the world, and possibly with the Transcendent. One girl commented that in HPE, "it tells us that you have to be kind, so not to be mean to other people who are not as good at sport as you. Also you need to be a good sport. Do not sought of say “Oh, I didn't win' and get all grumpy and walk away, or be mean to other people". Another student shared that it is most important that when working with others that you encourage: "say 'that was a good kick' and encourage others". To which other students supplemented that HPE physical activity lessons promotes cooperation. One learns to cooperate in HPE lessons by "working as a team", and you "learn how to cooperate in games". An example of the team sport "soccer" was given. One girl added, "we know that we can do group work together, then in sport and PE we know we can do team work together" insinuating that the skills needed are similar, if not the same and that there is a strong relationship binding the two. The students identified that they have different strengths and weaknesses when it comes to physical skills. One girl shared, "I'm good at basketball, swimming and shot-put. I'm not that good at long jump or high jump. I can't really make high jump". Another boy then said, "I'm good at Tae Kwon Do, soccer and shot-put and I'm not good at high jump or long jump".

\section{Summary of Cross-case Analysis}

Overall, student participants verbally and physically articulated connections through the physical activity strand that can be identified as spiritual experiences in HPE. The students who verbally identified strong connections were from Case Study School Two and Three and therefore had a specialist or designated HPE teacher and regularly participated in HPE physical activity lessons. Early years' student participants in all three case study schools did not verbally express connections between HPE experiences with other learning areas, or elaborate on spiritual concepts during focused group interviews. However, they did display what could be described as the children's spirituality characteristic of "felt sense", where "Individuals encounter and act upon the world with the whole of their bodies" (Hyde 2008, p. 120). Hyde et al. (2012, p. 3) report that this is a "challenge for those who work with children to recognise that many of these activities could be experienced by children as spiritual".

The majority of upper year's student participants and many middle year's student participants from all three Case Study Schools connected HPE and the RE Christian expression of spirituality, as well as spirituality generally. This was mainly through the 
promotion of Christian Gospel values in the physical activity strand. One child described "you feel better, about yourself and you have more self-esteem" which relates directly to the strong link between self-esteem and spirituality that Robbins et al. (2011) assert. Again, there was an increase in verbal articulation of links in schools that had an HPE specialist or designated teacher, where lessons were conducted regularly. Observations suggested that quality physical activity lessons promoted student interest (Table 4) and maximised physicality, bodily awareness and relationships.

\section{Discussion}

The data gathered in this study supports that there are expressions of children's spiritual cognizance and opportunities within HPE lessons. Harris (2007) defines children's spirituality as "transformational, directive, and peer-relational which involves actively living by being innately connected to a natural source within the moral universe, and affectively belonging with relationships that are interconnected within a child's culture and community". Student participants verbally articulated connections mainly through the physical activity strand. While connections are of a personal nature, they can be identified as spiritual experiences in HPE.

Children in the early years of the schools did not express spirituality verbally. This is reasoned by Hyde et al. (2012), professing that young children often are unable to articulate verbally their thoughts. However, physical activity lesson observations did display children acting upon the world with the whole of their bodies, subsequently becoming "far more in tune with their physicality" (2012, p. 3). Thus, young student participants (early years) displayed the children's spirituality characteristic of "felt sense".

Where the physical activity strand was of quality implementation, the HPE teacher acted as director and facilitator, peer relations were empathetic, accepting, and encouraging which enabled the children to truly belong and feel appreciated within the community of the school. Hence, this was consistent with the concepts of relationships, self, community, and culture. "In its purest sense, spiritual wellness involves cultivating beliefs, principles, and values that provide guidance and strength throughout all of life's experiences" (Robbins et al. 2011, p. 10). In Case Study Two School where HPE quality teaching and learning was experienced regularly, children's verbal articulation and observed physical engagement of spiritual expressions were increased. The connection between physicality and bodily awareness was observed for all lessons when children were engaged. For this reason, the data gathered within this research study implies that implementation of quality physical activity lessons increased spiritual connections. In quality HPE physical activity lessons, safety was optimal, children were involved in maximum participation, activities were challenging and differentiated for the engagement of all students, and lessons were inclusive and enjoyed. Hence, opportunities for students to experience the children's spirituality characteristic of "felt sense" were observed more frequently.

In Case Study Two School the children in middle and upper years articulated spiritual experiences through observations and interview. In being attuned to their physical, bodily knowing, these children appeared to have engaged their whole selves in direct, experiential, and concrete ways. The children were absorbed in experiences that seemed to bridge the divide between self and object (Hyde 2008, p. 121). As one middle years' student participant described, "Um, you feel like you're going do it and like you're not going to stop and it's going to help you run and you're not going to hurt yourself". The boy was 
explaining the importance of the HPE physical activity strand learning area as he "draws on the wisdom of his own body as a natural and primal way of knowing. It involves an awareness of the immediacy of experience and tactile, sensory activity" (Hyde 2010, p. 510).

The characteristic " "spiritual questing', refers to the fact that children are seekers. They are actively searching for a sense of life's meaning and purpose, and this is often reflected in what they claim to value most" (2010, p. 514). The children in the upper years' group of Case Study Two School valued team sports. One boy stated that he preferred team sports to individual: "It's better than individual, because like, if you like, if you make a mistake or something, there are people to help you out and stuff". Another girl mentioned that within cooperative team work, she enjoyed experiencing "good team spirit". She shared that she enjoyed working together and that it was fun to know that you could enjoy working with other people in the group. All student participants agreed that they do look out, back up, and support their team mates.

The data generated suggest that a WSCP for HPE increases the likelihood of quality experiences for the children in schools by increasing the rate of developmentally appropriate activities. This resulted in enhanced student interest; a positive effect on students' attitudes towards physical activities and spiritual connections (Table 4). Also, specialist teachers are associated with quality delivery of all dimensions of HPE which includes the spiritual dimension of the HPE curriculum (Queensland School Curriculum Council 1999a).

Furthermore, the data gathered are consistent with the literature, which states that HPE may hold particular significance and valuable spiritual experiences for children in relation to good health and well-being (Queensland School Curriculum Council 1999b). Specifically, within BCE this connection is acknowledged by the document "Religious Education Support Resource for the Early Years-RE and Health and Physical Learning Organising Ideas" (Catholic Education Archdiocese of Brisbane 2010). Catholic identification in Catholic schools has in recent times been forced to undergo major changes (Crotty 1998), and heavy reliance on RE is limiting (Berryman 1997). The physical dimension offers unique opportunities for children, opening many possibilities for the teaching practice within Catholic education as well as other religious and non-religious schools.

\section{Conclusion}

This study explored spirituality within the HPE learning area, through investigating children's experiences within three BCE primary schools of varying enrolment sizes. Literature evidences physicality having strong connections to spirituality, throughout the history of Catholic education and in contemporary curriculum documents. The data gathered supported the literature, evidencing that physical activities, and personal development strands in the HPE learning area are closely associated with children's everyday school community and culture. Thus, offering potential, arguably more so than other learning areas, for the development of spirituality.

Spirituality is an essential aspect of all human beings which needs to be given the opportunity to grow (Lavery and Hay 2004). Therefore, HPE should be embraced in all schools for its ability to offer opportunities in a holistic manner. For the context of this study, it should be embraced by every Catholic school, as a powerful medium to provide students with an abundance of practical and social experiences and the ideal environment for children to "innately connect to a natural source within the moral universe" (Harris 
2007, p. 264). However, Hyde et al. (2012) profess that teachers are challenged by recognising that enjoyable physical learning through non-verbal avenues can be spiritual.

This potential for spirituality can be capitalised by assuring HPE curriculum is delivered in a quality manner. The data gathered suggest that the opportunity for spiritual experiences would be increased through primary schools having a WSCP for HPE and a specialist HPE teacher where lessons are regularly provided. As this research study was only a small-scale sample, the data generated were limited by its nature. Hence, it is recommended that a large-scale research project be conducted to ascertain verisimilitude of findings pertinent to other schools and other education systems, within Australia and globally.

\section{References}

Anfara, V. A., Jr., Brown, K. M., \& Mangione, T. L. (2002). Qualitative analysis on stage: Making the research process more public. Educational Researcher, 31(7), 28-38.

Australian Bureau of Statistics. (2010). Schools Australia: 2010. Retrieved from http://www.abs.gov.au/ ausstats/abs@.nsf/lookup/4221.0Main+Features32010? OpenDocument.

Australian Curriculum, Assessment and Reporting Authority. (2012). Draft shape of the Australian curriculum: Health and physical education. Sydney: ACARA.

Bassey, M. (1999). Case study research in educational settings. Buckingham, UK: Open University Press.

Berryman, J. W. (1997). Spirituality, religious education, and the dormouse. International Journal of Children's Spirituality, 2(1), 9-22.

Berryman, J. W. (2009). Teaching godly play: How to mentor the spiritual development of children. Denver, CO: Morehouse Education Resources.

Buchanan, M., \& Hyde, B. (2008). Learning beyond the surface: Engaging the cognitive, affective and spiritual dimensions within the curriculum. International Journal of Children's Spirituality, 13(4), 309-320.

Catholic Education Archdiocese of Brisbane. (2003). Religious education years 1 to 10 learning outcomes. Brisbane: Brisbane Catholic Education Printery staff.

Catholic Education Archdiocese of Brisbane. (2010). Religious education support resource for the early years: Religious education and health and physical learning. Brisbane: Resource Link.

Catholic Education Commission, New South Wales. (1993). Towards wholeness-Catholic perspective on personal development, health and physical education years 7-10. Sydney: Catholic Education Commission, N.S.W.

Crotty, L. (1998). The religious education coordinator: Evolution and evolving agendas. Word of Life: Journal of Religious Education, 46(2), 8-14.

de Souza, M. (2005). Engaging the mind, heart and soul of the student in religious education: Teaching for meaning and connection. Journal of Religious Education, 53(4), 40-47.

de Souza, M. (2009). Spirituality and wellbeing. International Journal of Children's Spirituality, 14(3), $181-184$.

Feeney, R. (1995). A Catholic perspective: Physical exercise and sports. Leesburg, VA: Aquinas Press.

Gallagher, M. (1997). Clashing symbols -An introduction to faith and culture. London: Darton, Longman \& Todd.

Glaser, B. G., \& Strauss, A. L. (1967). The discovery of grounded theory. Chicago: Aldine.

Glesne, C. (1999). Becoming qualitative researchers: An introduction. Sydney: Addison Wesley Longman.

Grace, D. (2000). Values, sport and education. Journal of Christian Education, 43(2), 7-18.

Grainger, T., \& Kendall-Seatter, S. (2003). Drama and spirituality: Reflective connections. International Journal of Children's Spirituality, 8(1), 25-32.

Harris, K. (2007). Re-conceptualising spirituality in the light of educating young children. International Journal of Children's Spirituality, 12(3), 263-275.

Hater, R. (1994). New visions, new directions. Texas: Tabor.

Hay, D., \& Nye, R. (2006). The spirit of the child (Rev ed.). London: Jessica Kingsley Publishers.

Hughes, P., Thompson, C., Pryor, R., \& Bouma, G. (1995). Believe it or not: Australian spirituality and the churches in the 90s. Melbourne: Christian Research Association. 
Hyde, B. (2008). The identification of four characteristics of children's spirituality in Australian Catholic primary schools. International Journal of Children's Spirituality, 13(2), 117-127.

Hyde, B. (2010). Godly play nourishing children's spirituality: A case study. Religious Education, 105(5), 504-518.

Hyde, B., Ota, C., \& Yust, K. (2012). Spirituality and physicality. International Journal of Children's Spirituality, 17(1), 1-3.

Imbrosciano, A. (2000). Post modern religious education. Religious Education Journal of Australia, 16(2), $1-14$.

John Paul II. (1979). May 28. Address to directors and athletes of the Milan football team about the values of sports. L'Osservatore Romano (English edition), 583(22), 4.

John Paul II. (1980), November 3. Message to participants in the Twelfth Youth Games held in Rome, urges them to integrate physical gifts with spiritual ones. L'Osservatore Romano (English edition), 656(44), 10.

Kealey, R. (1985). Curriculum in the Catholic school. New York: National Catholic Education Association.

Lavery, S., \& Hay, P. (2004). Promoting our interior life as teachers. Catholic School Studies, 77(1), 2-3.

Lynch, T. (2004). A Catholic education perspective on the importance of the HPE curriculum in schools. ACHPER Healthy Lifestyles Journal, 51(2-3), 7-11.

Macdonald, D. (2003). Curriculum change and the post-modern world: Is the school curriculum-Reform movement an anachronism? Journal of Curriculum Studies, 35(2), 139-149.

Macdonald, D., \& Glover, S. (1997). Subject matter boundaries and curriculum change in the health and physical education key area. Curriculum Perspectives, 17(1), 23-30.

Malone, P., \& Ryan, M. (1994). Sound the trumpet: Planning and teaching religion in the Catholic primary school. Sydney: Social Science Press.

Merriam, S. (1998). Qualitative research and case study applications in education: Revised and expanded from case study research in education. San Francisco: Jossey-Bass.

Ministerial Council on Education, Employment, Training and Youth Affairs (MCEETYA). (1995). National report on schooling in Australia 1995. Carlton, VIC: Curriculum Corporation.

Mountain, V. (2011). Four links between child theology and children's spirituality. International Journal of Children's Spirituality, 16(3), 261-269.

Neuman, W. (2000). Social research methods: Qualitative and quantitative approaches. Sydney: Allyn and Bacon.

Patton, M. Q. (1990). Qualitative evaluation and research methods. London: Sage.

Queensland School Curriculum Council. (1999a). Health and physical education initial inservice materials. Brisbane: Publishing Services, Educational Queensland.

Queensland School Curriculum Council. (1999b). Health and physical education years 1 to 10 sourcebook. Brisbane: Publishing Services, Education Queensland.

Robbins, G., Powers, D., \& Burgess, S. (2011). A wellness way of life (9th ed.). USA: McGraw Hill.

Stake, E. (1994). Handbook of qualitative research. Thousand Oaks, CA: Sage.

Tinsey, W. (2002). The gospel in culture. Journal of Reigious Education, 50(3), 1-55.

Wellington, J. (2000). Educational research: Contemporary issues and practical approaches. London: Continuum. 